26(3), 549-568

\title{
Conversion between Decrement Models using Cubic Spline
}

\author{
Kim Ju Kyung ${ }^{a}$ · Lee Hangsuck ${ }^{b, 1}$ \\ ${ }^{a}$ Dongbu Insurance; ${ }^{b}$ Department of Actuarial Science/Mathematics, Sungkyunkwan University
}

(Received May 23, 2013; Revised June 14, 2013; Accepted June 17, 2013)

\begin{abstract}
This paper discusses conversion methods between multiple decrement models and associated single decrement models. One of most popular assumptions on fractional age is UDD(uniform distribution of decrement) or constant force of mortality in actuarial practice. Instead of these assumptions, this paper suggests cubic spline interpolation to approximate the distribution of fractional age with the continuous force of decrements. Conversion formulas are derived. The comparisons of these two methods based on the numerical data show that the cubic spline interpolation approach is more accurate.
\end{abstract}

Keywords: Multiple decrement, associated single decrement, cubic spline interpolation, continuously force of decrement, uniform distribution of decrement.

\section{1. 서론}

보험계약에는 보장내용에 따라 고려해야 하는 복합적이고 다양한 탈퇴요인들이 있기 때문에 보험회사 는 보험료 및 책임준비금 산출을 위하여 각 탈퇴요인별 발생확률인 다중탈퇴율(multiple decrement rates)이 필요하다. 탈퇴율에는 다중탈퇴율과 절대탈퇴율이 있다. 다중탈퇴율은 여러 탈퇴요인이 존재 하는 가운데 특정요인으로 탈퇴할 확률을 나타낸다. 반면에 절대탈퇴율은 탈퇴요인이 한 가지만 존재한 다고 가정한 가운데 탈퇴가 일어날 확률을 나타낸다.

일반적으로 다양한 탈퇴요인을 포함하는 보험계약의 보험료 및 책임준비금 산출에는 다중탈퇴율이 사용 되어야 한다. 그러나 다중탈퇴율은 보험상품의 판매 후 집적된 경험통계로 얻을 수 있게 되므로 보험회 사가 보험상품의 판매를 준비하는 시점에서는 다중탈퇴율을 구하기 어려운 점이 있다. 따라서 새로운 보험상품을 준비하는 단계에선 절대탈퇴율을 다중탈퇴율로 전환하여 사용하게 되고 두 탈퇴율간의 전환 방법은 중요한 문제가 된다.

다중탈퇴모형에 대한 선행연구는 다음과 같다. Bowers 등 (1997)의 10장에서 다중탈퇴모형에 대한 자 세한 설명과 절대탈퇴율과 다중탈퇴율 전환과정에 대하여 포괄적으로 다루고 있다. Shiu (1987)는 리 만 스틸지 적분(Riemann-Stieltjes Integration)을 이용하여 다중탈퇴율을 절대탈퇴율로 표현하는 일반 적인 정의를 활용하여 절대탈퇴율을 다중탈퇴율로 전환하는 과정을 제시하였다. Daniel (1993)은 조

\footnotetext{
${ }^{1}$ Corresponding author: Associate Professor, Department of Actuarial Science/Mathematics, Sungkyunkwan University, 25-2, Sungkyunkwan-ro, Jongno-gu, Seoul 110-745, Korea. E-mail: hangsuck@skku.edu
} 
건부 확률을 이용한 대안적인 절대탈퇴율을 정의하여 다중탈퇴모형과의 관계를 살펴보았다. Carriere (1994)는 다중탈퇴모형에 탈퇴요인들 사이의 종속성(dependency)을 반영한 연구를 진행하였다. 참고 로 생명표의 작성 및 추정에 대한 연구는 Golbeck (1986)과 London (1997)에서 논의되었다. Willmot (1997)은 UDD 가정의 일반적인 경우인 FI(Fractional Independence) 가정에서 다중탈퇴모형을 포함 한 여러 공식을 유도하였으며 Jones와 Mereu $(2000,2002)$ 는 fractional age 가정에 여러 가지 분포를 고려하여 연구를 진행하였다. Lee (2008)은 UDD 가정에서 연 기준 절대탈퇴율을 월 기준 다중탈퇴율 로 전환하는 공식과 UDD 가정 또는 상수탈퇴력 가정에서 연 기준 다중탈퇴율을 월 기준 절대탈퇴율로 전환하는 공식을 유도하였다.

하지만 위의 선행연구에서는 다중탈퇴율을 절대탈퇴율로 전환할 때 소수연령분포에 대하여 균등분 포(uniform distribution of decrement)가정과 상수탈퇴력(constant force of decrement)가정을 많이 사용하고 있고 절대탈퇴율을 다중탈퇴율로 전환할 때에는 균등분포가정을 주로 사용하고 있다. 그런데 이러한 가정을 사용하는 경우 탈퇴력(force of decrement)이 정수점에서 불연속적이라는 특징이 있으 며, 이러한 특징은 전환시 발생하는 오차와 무관하지 않다. Lee (2008)에서는 기존 가정을 이용하는데 있어서 유발되는 오차를 개선하기 위하여 대안적인 전환방법에 대한 연구가 필요하다고 지적한바 있다.

본 연구에서는 전환과정을 통하여 오차가 발생되는 문제점을 개선하기 위하여 삼차 스플라인 보간 법(cubic spline interpolation)을 이용하여 다중탈퇴율과 절대탈퇴율 상호간의 전환방법을 제안하고 수 치 예를 통하여 전환오차의 개선을 확인한다. 기존의 연구에서 탈퇴력의 불연속적인 특성으로 전환오차 가 생기는 점을 개선하기 위하여 연속적인 특성을 가지고 있는 삼차 스플라인 보간법을 이용한 탈퇴력 함수를 본 연구에서 이용하게 되었다.

본 연구의 구성은 서론에 이어 2 절에서 다중탈퇴모형과 절대탈퇴모형 그리고 탈퇴율의 전환공식에 대한 이론적 배경을 소개하고 3 절에서 수치 예를 통하여 모형간의 전환시 발생하는 전환오차의 문제점에 대 하여 살펴본다. 그리고 4 절에서 삼차 스플라인 보간법을 이용하여 탈퇴율간의 전환공식을 유도하는 알 고리듬을 제안하고 기존 가정하에서의 결과와 비교해보려 한다. 마지막으로 5 절에서 결론으로 논문을 마무리한다.

\section{2. 다중탈퇴모형과 절대탈퇴모형}

\section{1. 다중탈퇴모형(multiple decrement models)}

다중탈퇴모형은 여러 개의 탈퇴요인이 있는 가운데 그 중 특정요인으로 일정기간 중에 탈퇴가 발생할 확률을 나타내는 모형이다. 다중탈퇴모형의 설명에 필요한 기호와 확률변수 및 그 내용은 다음과 같다. 자세한 논의는 Bowers 등 (1997, pp. 307-308)을 참조하라.

$(x)$ 는 $x$ 세 연령을 가진 사람을 뜻하며 $T(x)$ 는 그 사람이 향후 탈퇴하는데 걸리는 시간을 나타내며 $J(x)$ 는 탈퇴요인을 나타낸다. 두 개의 확률변수 $T$ 와 $J$ 로 이루어진 결합확률밀도함수를 $f_{T, J}(t, j)$ 로, $J$ 에 대한 주변확률함수는 $f_{J}(j)$ 로, 그리고 $T$ 에 대한 주변확률밀도함수는 $f_{T}(t)$ 로 표현하기로 한다. 결 합확률밀도함수 $f_{T, J}(t, j)$ 는 $T$ 와 $J$ 로 정의된 확률을 계산할 때 사용한다. 시점 $t$ 와 시점 $t+d t$ 사이에 서 탈퇴요인 $j$ 로 인해 탈퇴할 확률은

$$
f_{T, J}(t, j) d t=\operatorname{Pr}\{(t<T \leq t+d t) \cap(J=j)\}
$$

이며, 시점 0 부터 시점 $t$ 사이에 탈퇴요인 $j$ 로 인해 탈퇴할 확률은

$$
\int_{0}^{t} f_{T, J}(s, j) d s=\operatorname{Pr}\{(0<T \leq t) \cap(J=j)\}
$$


이다. 그리고 $a$ 시점과 $b$ 시점 사이에서 탈퇴요인과 상관없이 탈퇴할 확률은

$$
\sum_{j=1}^{m} \int_{a}^{b} f_{T, J}(t, j) d t=\operatorname{Pr}\{a<T \leq b\}
$$

이다.

따라서 식 (2.2)를 이용하고 탈퇴요인 $j$ 를 상첨자로 표기하여 다중탈퇴율은

$$
{ }_{t} q_{x}^{(j)}=\int_{0}^{t} f_{T, J}(s, j) d s, \quad t \geq 0, j=1,2, \ldots, m
$$

로 정의하고

$$
{ }_{t} p_{x}^{(j)}={ }_{\infty} q_{x}^{(j)}-{ }_{t} q_{x}^{(j)}
$$

과 같은 기호로 정의한다. 식 (2.5)의 우변의 첫째항은 탈퇴요인 $j$ 로만 탈퇴가 발생할 확률이므로 1 이 아니다. 총 탈퇴율과 유지율 및 총탈퇴력은 다음과 같이 각각 정의된다.

$$
\begin{aligned}
{ }_{t} q_{x}^{(\tau)} & =\operatorname{Pr}\{T \leq t\}=F_{T}(t)=\int_{0}^{t} f_{T}(s) d s, \\
{ }_{t} p_{x}^{(\tau)} & =\operatorname{Pr}\{T>t\}=1-{ }_{t} q_{x}^{(\tau)}, \\
\mu_{x}^{(\tau)}(t) & =-\frac{d}{d t} \log _{t} p_{x}^{(\tau)} .
\end{aligned}
$$

그리고 식 (2.8)로부터 유지율은

$$
{ }_{t} p_{x}^{(\tau)}=e^{-\int_{0}^{t} \mu_{x}^{(\tau)}(s) d s}
$$

이 된다. 여기서, $j$ 를 탈퇴요인으로 하는 탈퇴력(force of decrement due to cause $j$ )은

$$
\mu_{x}^{(j)}(t)=\frac{f_{T, J}(t, j)}{1-F_{T}(t)}=\frac{f_{T, J}(t, j)}{{ }_{t} p_{x}^{(\tau)}}
$$

과 같이 표현되며 이는 또한 $x+t$ 시점에서의 탈퇴요인 $j$ 에 의한 순간적인 탈퇴발생률을 의미한다. 그 리고 식 (2.10)은 식 (2.4)에 의하여 다음과 같이 표현될 수도 있다.

$$
\mu_{x}^{(j)}(t)=\frac{1}{{ }_{t} p_{x}^{(\tau)}} \frac{d}{d t}{ }_{t} q_{x}^{(j)} .
$$

위의 식 (2.6)과 식 (2.4) 그리고 확률변수 $T$ 의 주변확률밀도함수를 이용하여 다음과 같이

$$
{ }_{t} q_{x}^{(\tau)}=\int_{0}^{t} f_{T}(s) d s=\int_{0}^{t} \sum_{j=1}^{m} f_{T, J}(s, j) d s=\sum_{j=1}^{m} \int_{0}^{t} f_{T, J}(s, j) d s=\sum_{j=1}^{m}{ }_{t} q_{x}^{(j)} .
$$

표현이 가능하며 식 (2.12)와 식 (2.11) 그리고 식 (2.8)을 이용하면 다음의 관계식이 생긴다.

$$
\mu_{x}^{(\tau)}(t)=\sum_{j=1}^{m} \mu_{x}^{(j)}(t)
$$

이 식의 의미는 총 $m$ 개의 탈퇴요인이 존재할 때 각각의 개별 탈퇴력의 합이 총탈퇴력과 같다는 것이다. 마지막으로 식 (2.4)는 다음과 같이 표현될 수도 있다.

$$
{ }_{t} q_{x}^{(j)}=\int_{0}^{t}{ }_{s} p_{x}^{(\tau)} \mu_{x}^{(j)}(s) d s .
$$




\section{2. 절대탈퇴모형(associated single decrement models)}

절대탈퇴모형은 다중탈퇴모형과는 달리 다른 탈퇴요인은 무시한 채 하나의 탈퇴요인만을 고려하는 모형 이다. 자세한 논의는 Bowers 등 (1997, pp. 319-321)을 참고하라. 절대탈퇴모형의 절대탈퇴율과 절대 유지율은 각각 다음과 같이 표현된다.

$$
\begin{aligned}
& { }_{{ } p_{x}^{\prime(j)}}=\exp \left[-\int_{0}^{t} \mu_{x}^{(j)}(s) d s\right], \\
& { }_{t} q_{x}^{\prime(j)}=1-{ }_{t} p_{x}^{\prime(j)} .
\end{aligned}
$$

위의 식에서 볼 수 있는 ', '는 다중탈퇴율과 구분하기 위한 기호이며 다중/절대탈퇴모형의 탈퇴력은 다 음과 같은 성질을 갖고 있다.

$$
\mu_{x}^{(j)}=\mu_{x}^{\prime(j)}
$$

그러므로 식 (2.17)의 성질에 따라 식 (2.9)와 식 (2.13)을 이용하여

$$
{ }_{t} p_{x}^{(\tau)}=\exp \left\{-\int_{0}^{t}\left[\mu_{x}^{(1)}(s)+\mu_{x}^{(2)}(s)+\cdots+\mu_{x}^{(m)}(s)\right] d s\right\}
$$

으로 표현 가능하다. 그리고 다음과 같은 관계식을 유도할 수 있다.

$$
{ }_{t} p_{x}^{(\tau)}=\prod_{i=1}^{m}{ }_{t} p_{x}^{(i)} .
$$

추가적으로 개별 탈퇴력 $\mu_{x}^{(j)}$ 에 관하여 식 (2.15)의 양변에 로그를 취해 다음과 같이 만들 수 있으며

$$
\log _{t} p_{x}^{(j)}=-\int_{0}^{t} \mu_{x}^{(j)}(s) d s .
$$

위의 관계식을 미분하고 이를 탈퇴력에 대하여 정리하여 다음과 같은 결과를 얻을 수 있다.

$$
\mu_{x}^{(j)}(t)=\frac{\frac{d}{d t}\left({ }_{t} q_{x}^{\prime(j)}\right)}{{ }_{t} p_{x}^{\prime(j)}} .
$$

\section{3. 다중탈퇴모형에서 절대탈퇴모형으로의 전환}

실무에서는 다중탈퇴모형을 절대탈퇴모형으로 전환하는 방법에는 소수연령분포를 균등분포로 가정하는 방법과 상수탈퇴력을 가정하는 방법이 있다. 두 가정하에서의 전환공식에 대한 유도과정은 Bowers 등 (1997, pp. 322-323)에 자세히 소개되어 있으므로 생략한다. 다중탈퇴율을 절대탈퇴율로 전환하는 공 식은 다음과 같다.

$$
{ }_{r} p_{x}^{\prime(j)}=\left({ }_{r} p_{x}^{(\tau)}\right)^{\frac{s q_{x}^{(j)}}{s q_{x}^{(\tau)}}} .
$$

이 공식은 소수연령분포를 균등분포로 가정하거나 또는 상수탈퇴력으로 가정한 경우 모두 성립한다. 여 기서 $r$ 과 $s$ 는 0 과 1 사이의 실수이다. 그리고 상수탈퇴력을 가정하는 경우 탈퇴력은

$$
\mu_{x}^{(j)}(t)=\mu_{x}^{(j)}(0), \quad 0 \leq t<1
$$

이며 소수연령분포를 균등분포로 가정하는 경우 탈퇴력은

$$
\mu_{x}^{(j)}(t)=\frac{q_{x}^{(j)}}{1-t \cdot q_{x}^{(\tau)}}, \quad 0 \leq t<1
$$

가 된다. 
Table 3.1. Multiple decrement rates

\begin{tabular}{|c|c|c|c|}
\hline$x$ & $q_{x}^{(1)}$ & $q_{x}^{(2)}$ & $q_{x}^{(3)}$ \\
\hline 0 & 0.252000 & 0.098820 & 0.111987 \\
\hline 1 & 0.186000 & 0.108270 & 0.112746 \\
\hline 2 & 0.130000 & 0.119340 & 0.113802 \\
\hline 3 & 0.100000 & 0.131760 & 0.115209 \\
\hline 4 & 0.080000 & 0.145260 & 0.116976 \\
\hline 5 & 0.074000 & 0.159030 & 0.119135 \\
\hline 6 & 0.066000 & 0.173340 & 0.121716 \\
\hline 7 & 0.060000 & 0.188730 & 0.124745 \\
\hline 8 & 0.054000 & 0.205470 & 0.128250 \\
\hline 9 & 0.046000 & 0.224100 & 0.132259 \\
\hline 10 & 0.040000 & 0.243540 & 0.136813 \\
\hline 11 & 0.038000 & 0.264060 & 0.141933 \\
\hline 12 & 0.050000 & 0.285930 & 0.147660 \\
\hline 13 & 0.074000 & 0.310770 & 0.154015 \\
\hline 14 & 0.106000 & 0.338580 & 0.161039 \\
\hline 15 & 0.138000 & 0.369360 & 0.168767 \\
\hline 16 & 0.166000 & 0.403110 & 0.177233 \\
\hline 17 & 0.190000 & 0.439560 & 0.186466 \\
\hline 18 & 0.210000 & 0.477090 & 0.196512 \\
\hline 19 & 0.224000 & 0.515970 & 0.207400 \\
\hline
\end{tabular}

\section{4. 절대탈퇴모형에서 다중탈퇴모형으로의 전환}

절대탈퇴모형을 다중탈퇴모형으로 전환하는 방법에는 소수연령분포를 균등분포로 가정하는 방법을 사 용하는 것이 일반적이다. 절대탈퇴율을 다중탈퇴율로 전환하는 공식은 다음과 같다. Bowers 등 (1997, pp. 327-330)을 참고하라.

$$
{ }_{t} q_{x}^{(j)}={ }_{t} q_{x}^{\prime(j)} \int_{0}^{t}\left(\prod_{i \neq j}^{m}\left(1-s \cdot q_{x}^{(i)}\right)\right) d s .
$$

\section{3. 균등분포가정을 이용한 전환 방법의 문제점}

이 절에서는 앞에서 소개된 전환공식을 실제 데이터에 적용하여 직접적인 수치를 구하고 전환시 발생하 는 오차에 대하여 분석해보고자 한다. Table 3.1 과 같이 3 개의 탈퇴요인이 있는 다중탈퇴표를 알고 있 을 때 식 (2.22)와 식 (2.12)를 이용하면 Table 3.2와 같이 절대탈퇴표로 전환시킬 수 있다. 그리고 반대 로 Table 3.2 와 같은 절대탈퇴표를 알고 있을 때 식 (2.25)를 이용하면 Table 3.3 과 같이 다중탈퇴표로 전환시킬 수 있다.

전환공식을 이용하면 쉽게 다중탈퇴표를 절대탈퇴표로, 절대탈퇴표를 다중탈퇴표로 전환시킬 수 있다. 그런데 이렇게 전환된 수치들이 과연 어느 정도 정확한지에 대한 의문이 있다. 이러한 의문을 해소하기 위해서는 비교대상이 되는 절대탈퇴표와 다중탈퇴표가 있어야 한다. 그러나 이러한 자료를 구하기는 현 실적으로 어렵다. 따라서 오차에 대한 분석을 위해서 이 연구에서는 Figure 3.1과 같이 절대탈퇴표(또 는 다중탈퇴표)를 다중탈퇴표(또는 절대탈퇴표)로 전환시키고 이렇게 구한 다중탈퇴표(또는 절대탈퇴 표)를 다시 절대탈퇴표(또는 다중탈퇴표)로 전환시켜 처음에 알고 있던 절대탈퇴표(또는 다중탈퇴표)의 
Table 3.2. Associated single decrement rates

\begin{tabular}{|c|c|c|c|}
\hline$x$ & $q_{x}^{\prime(1)}$ & $q_{x}^{\prime(2)}$ & $q_{x}^{\prime(3)}$ \\
\hline 0 & 0.287057 & 0.124257 & 0.139603 \\
\hline 1 & 0.212439 & 0.129783 & 0.134770 \\
\hline 2 & 0.149156 & 0.137812 & 0.131858 \\
\hline 3 & 0.115573 & 0.149407 & 0.131940 \\
\hline 4 & 0.093281 & 0.162893 & 0.133404 \\
\hline 5 & 0.087184 & 0.178020 & 0.136585 \\
\hline 6 & 0.078619 & 0.193500 & 0.140157 \\
\hline 7 & 0.072364 & 0.210439 & 0.144589 \\
\hline 8 & 0.066042 & 0.228927 & 0.149788 \\
\hline 9 & 0.057153 & 0.249268 & 0.155667 \\
\hline 10 & 0.050570 & 0.270905 & 0.162632 \\
\hline 11 & 0.048996 & 0.294675 & 0.171087 \\
\hline 12 & 0.066046 & 0.323444 & 0.182730 \\
\hline 13 & 0.100837 & 0.360059 & 0.198461 \\
\hline 14 & 0.150283 & 0.405583 & 0.219180 \\
\hline 15 & 0.205552 & 0.459839 & 0.245281 \\
\hline 16 & 0.262955 & 0.523322 & 0.278017 \\
\hline 17 & 0.325768 & 0.598251 & 0.320806 \\
\hline 18 & 0.400196 & 0.686910 & 0.380177 \\
\hline 19 & 0.501526 & 0.798841 & 0.475133 \\
\hline
\end{tabular}

Table 3.3. Multiple decrement rates from Table 3.2

\begin{tabular}{cccc}
\hline$x$ & $q_{x}^{(1)}$ & $q_{x}^{(2)}$ & 0.112553 \\
\hline 0 & 0.250845 & 0.099409 & 0.112948 \\
1 & 0.185577 & 0.108491 & 0.113842 \\
2 & 0.129948 & 0.119352 & 0.115219 \\
3 & 0.100074 & 0.131676 & 0.116992 \\
4 & 0.080137 & 0.145106 & 0.119180 \\
5 & 0.074176 & 0.158809 & 0.121798 \\
6 & 0.066214 & 0.173044 & 0.124878 \\
7 & 0.060253 & 0.188345 & 0.128452 \\
8 & 0.054291 & 0.204977 & 0.132556 \\
9 & 0.046320 & 0.223483 & 0.137234 \\
10 & 0.040350 & 0.242769 & 0.142512 \\
11 & 0.038409 & 0.263072 & 0.148446 \\
12 & 0.050632 & 0.284513 & 0.155128 \\
13 & 0.075079 & 0.308578 & 0.162716 \\
14 & 0.107791 & 0.335112 & 0.171405 \\
15 & 0.140810 & 0.363911 & 0.181470 \\
16 & 0.170350 & 0.394523 & 0.193431 \\
17 & 0.196909 & 0.425685 & 0.208368 \\
19 & 0.221511 & 0.453724 & 0.229662 \\
\hline
\end{tabular}




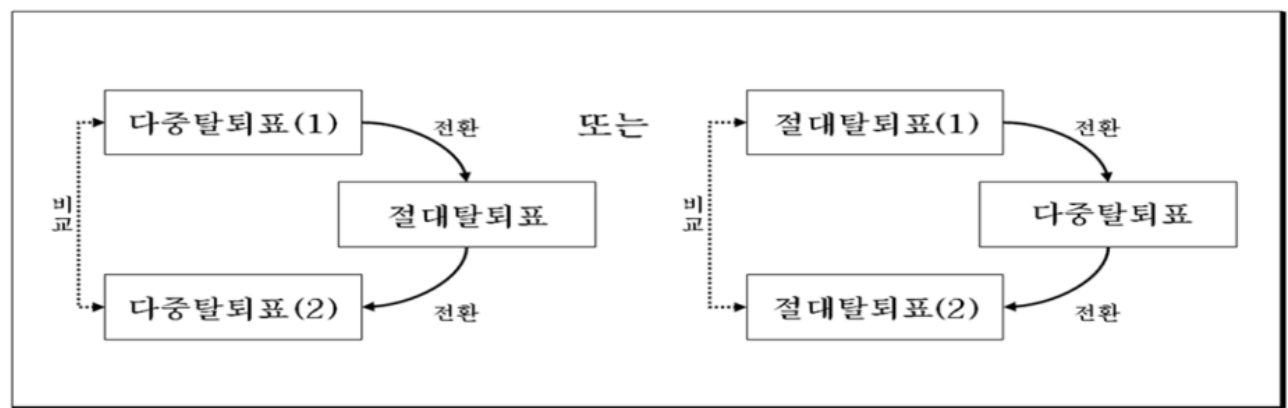

Figure 3.1. Conversion of decrement models

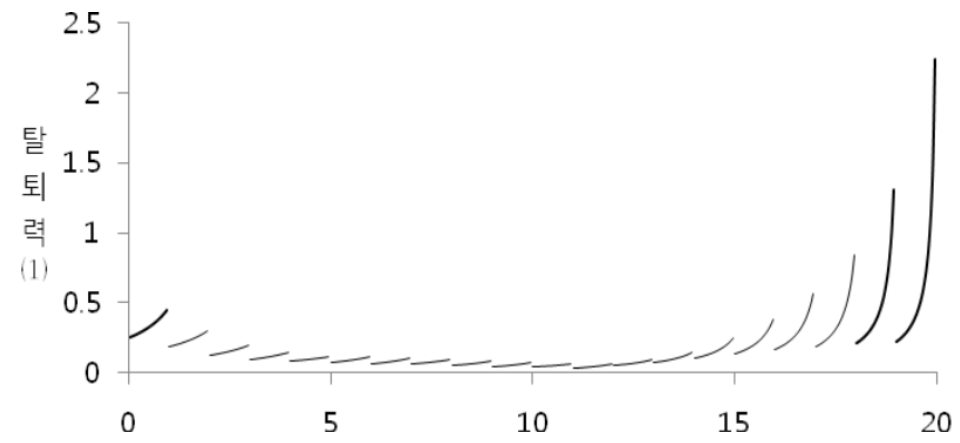

Figure 3.2. Force of decrement due to cause (1)

수치와 비교해보는 방법으로 오차를 분석해보고자 한다.

Figure 3.1의 방법을 이용하여 처음에 주어진 다중탈퇴표(Table 3.1)를 절대탈퇴표(Table 3.2)로 전환 시키고 다시 다중탈퇴표(Table 3.3)로 전환시킨 후 이를 처음의 다중탈퇴표(Table 3.1)와 비교해보면, 즉 Table 3.1과 Table 3.3를 비교해보면 수치들이 많은 차이가 나고 있음을 알 수 있다. 따라서 보다 정 밀한 전환방법이 요구된다.

기존의 전환방법(다중/절대탈퇴모형간의 전환에서 소수연령분포를 균등분포로 가정하는 방법과 상수탈 퇴력을 가정하는 방법)에서 전환오차가 발생하는 원인은 탈퇴력에서 찾을 수 있다. 그 이유는 다음과 같 다. 상수탈퇴력 가정의 경우 식 (2.23)과 같이 가정하고 있기 때문에 $t$ 가 1 에 매우 근접한 경우 다음과 같이

$$
\lim _{t \rightarrow 1-} \mu_{x}^{(j)}(t) \neq \mu_{x+1}^{(j)}(0)
$$

이므로 정수점에서 불연속적인 탈퇴력을 가진다. 일반적으로 사망률과 같은 탈퇴요인의 탈퇴력(사력)을 생각했을 때 연령별 탈퇴력이 불연속적이라는 생각은 들지 않는다. 따라서 이렇게 불연속적인 탈퇴력은 전환시 발생하는 오차의 원인일 수 있다. 또한 균등분포가정에서도 마찬가지로 Table 3.1과 같은 자료 가 주어졌을 때 식 (2.24)를 이용하여 탈퇴요인별 탈퇴력을 Figure 3.2, Figure 3.3, Figure 3.4와 같이 그려보면 정수점에서 불연속적임을 확인할 수 있다. 


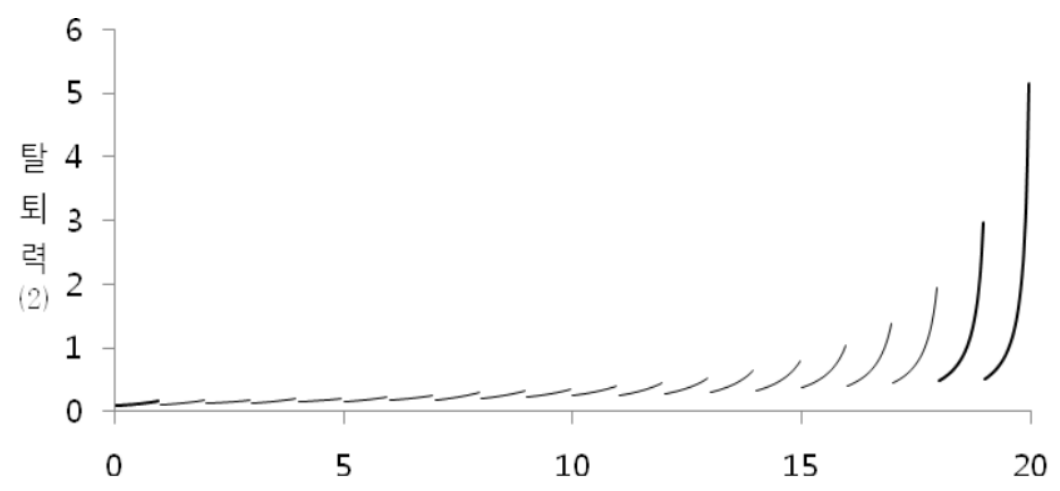

Figure 3.3. Force of decrement due to cause (2)

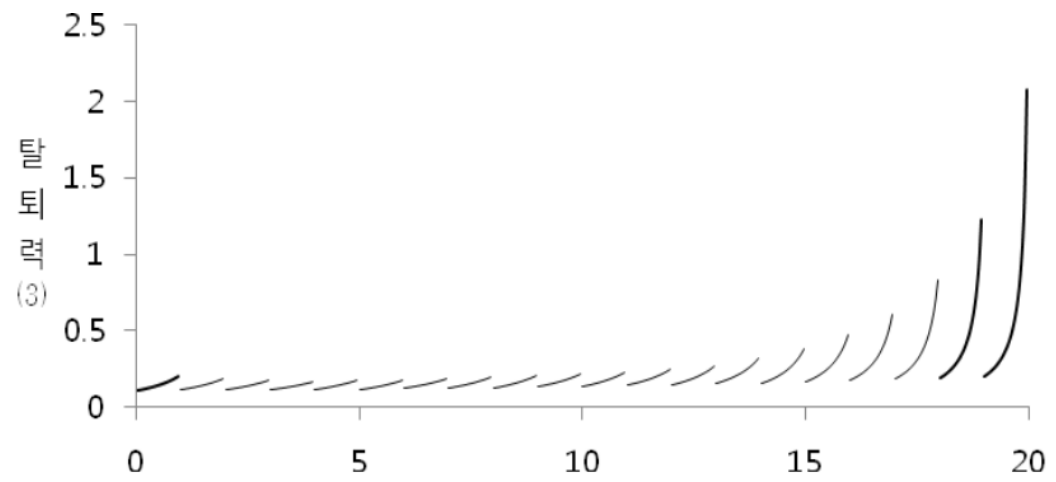

Figure 3.4. Force of decrement due to cause (3)

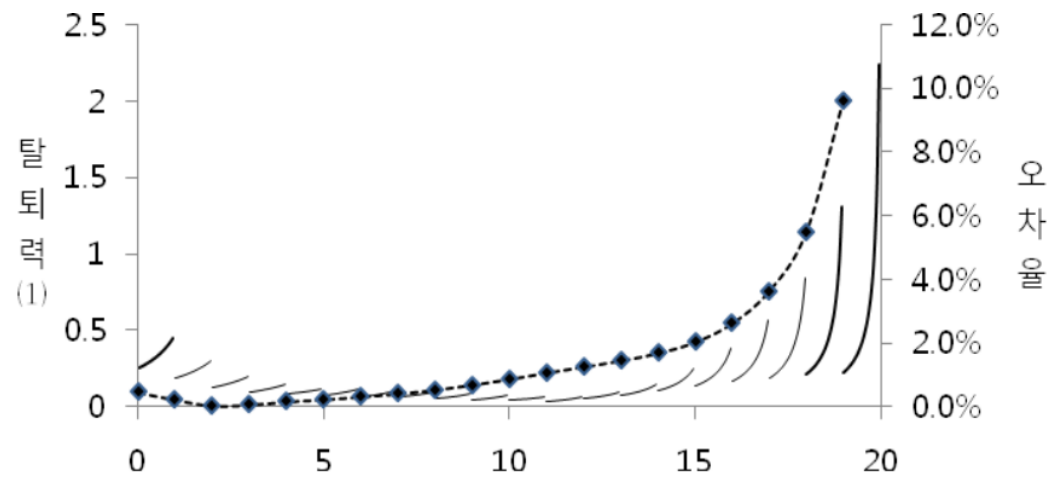

Figure 3.5. Relative conversion error of force of decrement (1)

불연속적인 탈퇴력이 다중/절대탈퇴모형간의 전환에서 발생하는 오차의 원인이 되는지는 Figure 3.5 , Figure 3.6, Figure 3.7과 같이 탈퇴율과 오차율을 비교한 그래프에서 탈퇴력의 변화가 심한 구간의 오 차가 높게 나타나는 것을 통하여 확인할 수 있다. 


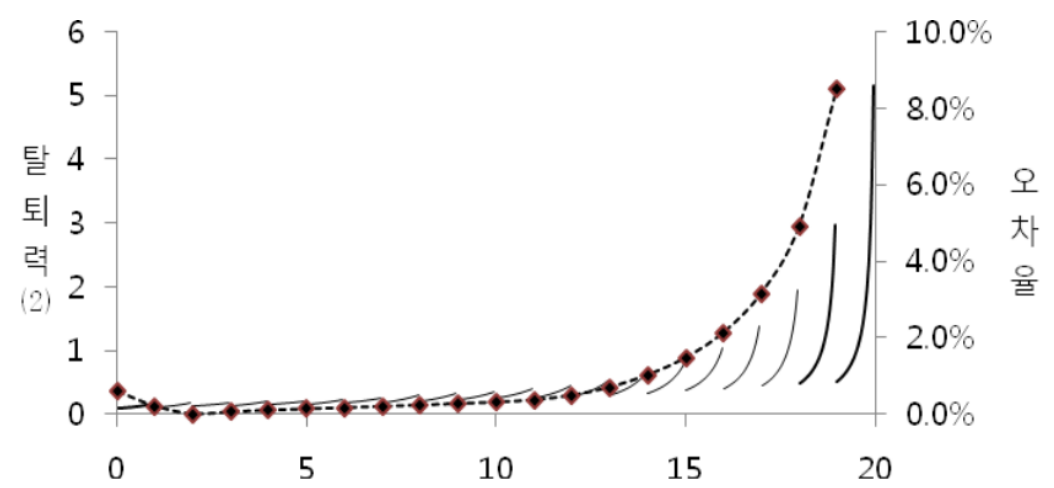

Figure 3.6. Relative conversion error of force of decrement (2)

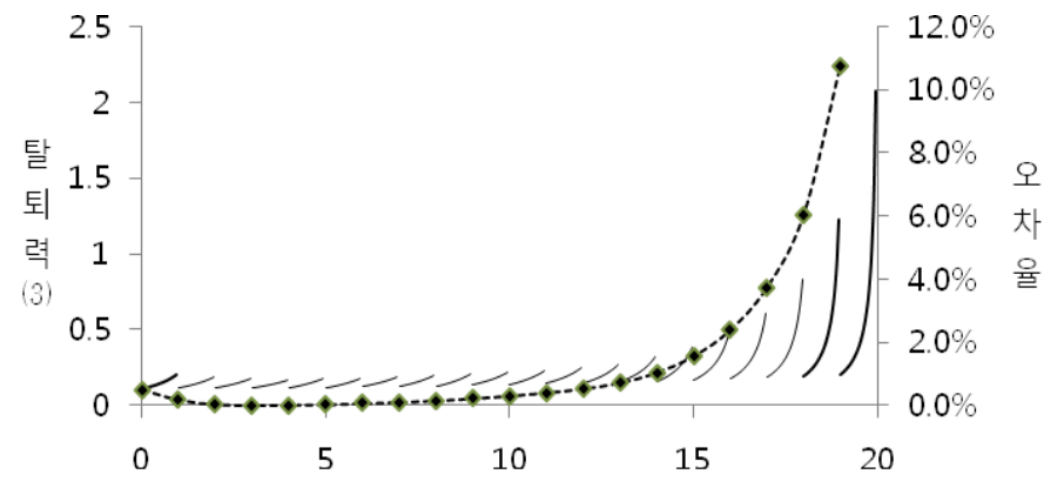

Figure 3.7. Relative conversion error of force of decrement (3)

\section{4. 삼차 스플라인 보간법을 이용한 탈퇴율의 전환 과정}

지금까지 기존 가정을 이용한 다중/절대탈퇴모형간의 전환공식에 대하여 알아보았다. 기존 가정의 문 제점으로 파악된 부분은 탈퇴력이 정수점에서 불연속이라는 사실이었다. 따라서 이 절에서 정수점에서 도 연속적인 탈퇴력을 가질 수 있는 방법에 대하여 알아보고자 한다.

\section{1. 삼차 스플라인 보간법(cubic spline interpolation)}

이 절에서는 앞으로 소개될 연속적인 탈퇴력을 만드는데 필요한 삼차 스플라인 보간법에 대하여 알아 보고자 한다. 삼차 스플라인 함수(cubic spline function)의 정의는 다음과 같다. 자세한 논의는 $\mathrm{Kim}$ (2000, pp. 138-145)를 참고하라

정의 4.1 (삼차 스플라인 함수) $a=x_{0}<x_{1}<\cdots<x_{n}=b$ 인 $(n+1)$ 개의 점 $\left\{\left(x_{i}, y_{i}\right) \mid i=\right.$ $0,1, \ldots, n\}$ 에 대하여 다음 조건을 만족하는 다항식 $Q(x)$ 가 유일하게 존재한다.

(1) $Q\left(x_{i}\right)=y_{i}, i=0,1, \ldots, n$.

(2) $Q(x)$ 는 소구간 $x_{i-1} \leq x \leq x_{i}, i=1,2, \ldots, n$ 에서 삼차다항식이다.

(3) $Q(x), Q^{\prime}(x), Q^{\prime \prime}(x)$ 는 구간 $a \leq x \leq b$ 에서 연속이다. 
그리고 다음의 조건까지 만족하면 $Q(x)$ 를 자연 삼차 스플라인 함수(natural cubic spline function)라 부른다.

(4) $Q^{\prime \prime}\left(x_{0}\right)=Q^{\prime \prime}\left(x_{n}\right)=0$.

위의 유일성에 대한 증명 부분은 수치해석교재를 참고하면 쉽게 찾을 수 있기 때문에 생략하기로 하며 삼차 스플라인 함수의 수식을 구하는 방법은 다음과 같다. $h_{i}=x_{i+1}-x_{i}$ 로 놓으면

$$
\begin{aligned}
Q_{i}(x)= & \frac{\left(x_{i+1}-x\right)^{3} c_{i}+\left(x-x_{i}\right)^{3} c_{i+1}}{6 h_{i}}+\frac{\left(x_{i+1}-x\right) y_{i}+\left(x-x_{i}\right) y_{i+1}}{h_{i}} \\
& -\frac{1}{6} h_{i}\left[\left(x_{i+1}-x\right) c_{i}+\left(x-x_{i}\right) c_{i+1}\right], \quad x_{i} \leq x \leq x_{i+1}
\end{aligned}
$$

이며 그리고 이때의 $c_{1}, c_{2}, \ldots, c_{n-1}$ 은 다음과 같은 조건 하에서의 $A c=b$ 의 해이다.

$$
\begin{aligned}
c & =\left(c_{i}\right)^{T}, \quad 1 \leq i \leq n-1, \\
b & =\left(b_{i}\right)^{T}, \quad b_{i}=\frac{6\left(y_{i+1}-y_{i}\right)}{h_{i}}-\frac{6\left(y_{i}-y_{i-1}\right)}{h_{i-1}}, \quad 1 \leq i \leq n-1, \\
\gamma_{i} & =2\left(h_{i}+h_{i-1}\right), \quad 1 \leq i \leq n-1, \\
A & =\left[\begin{array}{ccccccccc}
\gamma_{1} & h_{1} & 0 & 0 & \cdots & 0 & 0 & 0 & 0 \\
h_{1} & \gamma_{2} & h_{2} & 0 & \cdots & 0 & 0 & 0 & 0 \\
0 & h_{2} & \gamma_{3} & h_{3} & \cdots & 0 & 0 & 0 & 0 \\
& \vdots & & h_{i-1} & \gamma_{i} & h_{i} & & \vdots & \\
0 & 0 & 0 & 0 & \cdots & h_{n-4} & \gamma_{n-3} & h_{n-3} & 0 \\
0 & 0 & 0 & 0 & \cdots & 0 & h_{n-3} & \gamma_{n-2} & h_{n-2} \\
0 & 0 & 0 & 0 & \cdots & 0 & 0 & h_{n-2} & \gamma_{n-1}
\end{array}\right]
\end{aligned}
$$

\section{2. 다중탈퇴모형에서 절대탈퇴모형으로의 전환}

이 절에서는 앞에서 언급하였듯이 삼차 스플라인 함수를 이용하여 정수점을 포함한 전구간에서 연속적 인 탈퇴력을 정의하고 이를 이용하여 다중탈퇴율을 절대탈퇴율로 전환하는 공식을 유도하고자 한다.

2.1 절에서 소개한 탈퇴력을 나타내는 식 (2.11)은

$$
\mu_{x}^{(j)}(t)=\frac{1}{{ }_{t} p_{x}^{(\tau)}} \frac{d}{d t} t_{t}^{(j)}
$$

인데 미분을 해도 연속인 특성을 갖는 삼차 스플라인 함수로 유지율과 다중탈퇴율을 표현하고 식 (2.11)에 대입하여 탈퇴력을 만들면 전 구간에서 연속적인 탈퇴력을 얻을 수 있을 것이다. 우선 다 중탈퇴율을 삼차 스플라인 함수로 정의하기에 앞서 총 $m$ 개의 탈퇴요인을 가진 다중탈퇴율에 대하여 다 음과 같이

$$
\begin{gathered}
{ }_{x} q_{0}^{(j)}=Q^{(j)}(x), \\
Q^{(\tau)}(x)=\sum_{j=1}^{m} Q^{(j)}(x)
\end{gathered}
$$

정의하자. 식 $(4.1)$ 에서 $Q^{(j)}(x)$ 는 각 연령 $(i=0,1, \ldots, n)$ 간 소수연령구간을 나타내는 삼차 스플라인 
함수인 $Q_{i}^{(j)}(x)$ 를 연결한 것으로, $Q_{i}^{(j)}(x)$ 는 정의 4.1 에서 소개한 스플라인 함수 수식의 $x_{i}$ 와 $y_{i}$ 에 각각 연령 $(i)$ 과 그 연령까지 $j$ 요인으로 탈퇴할 확률 $\left(i q_{0}^{(j)}\right)$ 을 대입하여 도출할 수 있다.

유지율은 다음과 같이 삼차 스플라인 함수 $Q(x)$ 로 표현할 수 있다.

$$
\begin{aligned}
{ }_{t} p_{x}^{(\tau)} & =\frac{{ }_{t} p_{x}^{(\tau)} \cdot{ }_{x} p_{0}^{(\tau)}}{{ }_{x} p_{0}^{(\tau)}}=\frac{{ }_{x+t} p_{0}^{(\tau)}}{{ }_{x} p_{0}^{(\tau)}}=\frac{1-{ }_{x+t} q_{0}^{(\tau)}}{1-{ }_{x} q_{0}^{(\tau)}} \\
& =\frac{1-Q^{(\tau)}(x+t)}{1-Q^{(\tau)}(x)} .
\end{aligned}
$$

그리고 다중탈퇴율은 아래의 관계식

$$
{ }_{x+t} q_{0}^{(j)}={ }_{x} q_{0}^{(j)}+{ }_{x} p_{0}^{(\tau)} \cdot{ }_{t} q_{x}^{(j)}
$$

에 따라서 삼차 스플라인 함수로 아래와 같이 정의할 수 있다.

$$
\begin{aligned}
{ }_{t} q_{x}^{(j)} & =\frac{{ }_{x+t} q_{0}^{(j)}-{ }_{x} q_{0}^{(j)}}{{ }_{x} p_{0}^{(\tau)}}=\frac{{ }_{x+t} q_{0}^{(j)}-{ }_{x} q_{0}^{(j)}}{1-{ }_{x} q_{0}^{(\tau)}} \\
& =\frac{Q^{(j)}(x+t)-Q^{(j)}(x)}{1-Q^{(\tau)}(x)} .
\end{aligned}
$$

이제 삼차 스플라인 함수로 정의된 식 (4.2)와 식 (4.3)을 식 (2.11)에 대입하면 다음과 같이 전 구간에 서 연속적인 탈퇴력을 표현할 수 있다.

$$
\mu_{x}^{(j)}(t)=\frac{d}{d t}\left(\frac{Q^{(j)}(x+t)-Q^{(j)}(x)}{1-Q^{(\tau)}(x)}\right) /\left(\frac{1-Q^{(\tau)}(x+t)}{1-Q^{(\tau)}(x)}\right) .
$$

그런데 분자부분은

$$
\begin{aligned}
& \frac{d}{d t}\left(\frac{Q^{(j)}(x+t)-Q^{(j)}(x)}{1-Q^{(\tau)}(x)}\right) \\
& =\frac{\left(1-Q^{(\tau)}(x)\right) \frac{d}{d t}\left(Q^{(j)}(x+t)-Q^{(j)}(x)\right)-\left(Q^{(j)}(x+t)-Q^{(j)}(x)\right) \frac{d}{d t}\left(1-Q^{(\tau)}(x)\right)}{\left(1-Q^{(\tau)}(x)\right)^{2}} \\
& =\frac{\frac{d}{d t}\left(Q^{(j)}(x+t)\right)}{\left(1-Q^{(\tau)}(x)\right)}
\end{aligned}
$$

으로 간단히 정리되므로 식 (4.5)를 식 (4.4)에 대입하여 탈퇴요인에 대한 탈퇴력은

$$
\begin{aligned}
\mu_{x}^{(j)}(t) & =\frac{\frac{d}{d t}\left(Q^{(j)}(x+t)\right)}{\left(1-Q^{(\tau)}(x)\right)} /\left(\frac{1-Q^{(\tau)}(x+t)}{1-Q^{(\tau)}(x)}\right) \\
& =\frac{\frac{d}{d t}\left(Q^{(j)}(x+t)\right)}{1-Q^{(\tau)}(x+t)}
\end{aligned}
$$

이 된다. 절대유지율의 정의인 식 (2.15)에 탈퇴력을 나타내는 식 (4.6)을 대입하면

$$
\begin{aligned}
{ }_{t} p_{x}^{\prime(j)} & =\exp \left[-\int_{0}^{t} \mu_{x}^{(j)}(s) d s\right] \\
& =\exp \left[-\int_{0}^{t}\left(\frac{\frac{d}{d s}\left(Q^{(j)}(x+s)\right)}{1-Q^{(\tau)}(x+s)}\right) d s\right], \quad \text { 단 } Q^{(\tau)}(x)=\sum_{j=1}^{m} Q^{(j)}(x)
\end{aligned}
$$


이 된다.

\section{3. 절대탈퇴모형에서 다중탈퇴모형으로의 전환}

총 $m$ 개의 탈퇴요인을 가진 절대탈퇴모형에서 임의의 탈퇴요인 $j$ 로 인하여 시점 0 부터 시점 $x$ 사이에 탈퇴할 확률을 아래와 같이 삼차 스플라인 함수로 정의하고

$$
{ }_{x} q_{0}^{\prime(j)}=Q^{(j)}(x) .
$$

총 탈퇴율도 다음과 같이 삼차 스플라인 함수로 정의하면

$$
{ }_{x} q_{0}^{(\tau)}=1-\prod_{j=1}^{m}{ }_{x} p_{0}^{(j)}=1-\prod_{j=1}^{m}\left(1-Q^{\prime(j)}(x)\right)=Q^{(\tau)}(x)
$$

이 된다. 절대탈퇴율은 다음의 관계식

$$
\begin{aligned}
{ }_{x+t} q_{0}^{\prime(j)} & ={ }_{x} q_{0}^{(j)}+{ }_{x} p_{0}^{\prime(j)} \cdot{ }_{t} q_{x}^{\prime(j)}, \\
{ }_{t} q_{x}^{\prime(j)} & =\frac{{ }_{x+t} q_{0}^{(j)}-{ }_{x} q_{0}^{\prime(j)}}{{ }_{x} p_{0}^{(j)}}
\end{aligned}
$$

에 의하여 아래와 같이 삼차 스플라인 함수로 정의할 수 있다.

$$
{ }_{t} q_{x}^{\prime(j)}=\frac{Q^{\prime(j)}(x+t)-Q^{(j)}(x)}{1-Q^{\prime(j)}(x)} .
$$

그리고 식 (2.16)을 이용하면

$$
{ }_{t} p_{x}^{\prime(j)}=1-{ }_{t} q_{x}^{\prime(j)}
$$

이므로 절대유지율은 아래와 같이 삼차 스플라인 함수로 표현할 수 있다.

$$
\begin{aligned}
{ }_{t} p_{x}^{\prime(j)} & =1-\frac{Q^{\prime(j)}(x+t)-Q^{\prime(j)}(x)}{1-Q^{\prime(j)}(x)} \\
& =\frac{1-Q^{\prime(j)}(x+t)}{1-Q^{\prime(j)}(x)} .
\end{aligned}
$$

따라서 식 (4.10)과 식 (4.11)을 탈퇴력 함수인 식 (2.21)에 대입하면

$$
\mu_{x}^{(j)}(t)=\frac{d}{d t}\left(\frac{Q^{\prime(j)}(x+t)-Q^{\prime(j)}(x)}{1-Q^{\prime(j)}(x)}\right) /\left(\frac{1-Q^{\prime(j)}(x+t)}{1-Q^{\prime(j)}(x)}\right)
$$

을 얻을 수 있다. 분자부분은 다음과 같이

$$
\begin{aligned}
& \frac{d}{d t}\left(\frac{Q^{\prime(j)}(x+t)-Q^{\prime(j)}(x)}{1-Q^{\prime(j)}(x)}\right) \\
& =\frac{\left(1-Q^{\prime(j)}(x)\right) \frac{d}{d t}\left(Q^{\prime(j)}(x+t)-Q^{\prime(j)}(x)\right)-\left(Q^{\prime(j)}(x+t)-Q^{\prime(j)}(x)\right) \frac{d}{d t}\left(1-Q^{\prime(j)}(x)\right)}{\left(1-Q^{\prime(j)}(x)\right)^{2}} \\
& =\frac{\frac{d}{d t}\left(Q^{\prime(j)}(x+t)\right)}{\left(1-Q^{\prime(j)}(x)\right)}
\end{aligned}
$$


으로 정리되므로 식 (4.13)을 식 (4.12)에 대입하여

$$
\begin{aligned}
\mu_{x}^{(j)}(x) & =\frac{\frac{d}{d t}\left(Q^{\prime(j)}(x+t)\right)}{\left(1-Q^{\prime(j)}(x)\right)} /\left(\frac{1-Q^{\prime(j)}(x+t)}{1-Q^{\prime(j)}(x)}\right) \\
& =\frac{\frac{d}{d t}\left(Q^{\prime(j)}(x+t)\right)}{1-Q^{\prime(j)}(x+t)}
\end{aligned}
$$

과 같은 삼차 스플라인 함수로 구성되는 탈퇴력 함수를 도출할 수 있다.

따라서 이렇게 도출한 탈퇴력 함수를 이용하면 연속적인 탈퇴력을 이용하여 절대탈퇴율을 다중탈퇴율로 전환시킬 수 있게 되며 그 방법은 다음과 같다. 식 (2.14)는 탈퇴요인 $j$ 에 대한 다중탈퇴율을 나타내는 데 여기에 앞에서 구한 식 (4.14)를 대입하면

$$
\begin{aligned}
{ }_{t} q_{x}^{(j)} & =\int_{0}^{t}{ }_{s} p_{x}^{(\tau)} \mu_{x}^{(j)}(s) d s \\
& =\int_{0}^{t}{ }_{s} p_{x}^{(\tau)} \frac{\frac{d}{d t}\left(Q^{\prime(j)}(x+s)\right)}{1-Q^{\prime(j)}(x+s)} d s
\end{aligned}
$$

와 같아지고 유지율은

$$
{ }_{t} p_{x}^{(\tau)}=\frac{{ }_{x+t} p_{0}^{(\tau)}}{{ }_{x} p_{0}^{(\tau)}}=\frac{1-Q^{(\tau)}(x+t)}{1-Q^{(\tau)}(x)}
$$

이므로 이를 다시 식 (4.15)에 대입하면 다음과 같은 다중탈퇴율 전환공식을 도출할 수 있다.

$$
{ }_{t} q_{x}^{(j)}=\int_{0}^{t} \frac{\left(1-Q^{(\tau)}(x+s)\right) \frac{d}{d s}\left(Q^{\prime(j)}(x+s)\right)}{\left(1-Q^{(\tau)}(x)\right)\left(1-Q^{\prime(j)}(x+s)\right) d s}, \quad \text { 단, } Q^{(\tau)}(x)=1-\prod_{j=1}^{m}\left(1-Q^{\prime(j)}(x)\right) .
$$

\section{4. 연속탈퇴력가정과 기존 가정의 비교}

4.2 절과 4.3 절에서는 연속적인 탈퇴력 가정을 이용한 다중/절대탈퇴율간의 전환공식에 대하여 알아보 았다. 이번 절에서는 앞에서 도출한 전환공식을 실제 데이터에 적용시켜보고 기존 가정을 이용한 전환 방법의 결과와 비교해보고자 한다. 하지만 그에 앞서 삼차 스플라인 보간법으로 도출된 탈퇴력의 그래 프를 그려보고 기존의 균등분포가정 하에서의 탈퇴력 그래프와 비교해보고자 한다. 앞에서 제시되었던 Table 3.1을 다시 살펴보자.

Table 3.1은 다중탈퇴표이므로 식 (4.6)을 이용하여 탈퇴요인별 탈퇴력을 그려볼 수 있고 그 결과는 Figure 4.1과 같다.

그리고 균등분포가정 하에서의 탈퇴력 그래프와 식 (4.6)의 탈퇴력 그래프를 탈퇴요인별로 각각 Figure $4.2 \sim 4.4$ 와 같이 비교해보았다. 그 결과 삼차 스플라인 함수를 이용한 탈퇴력의 그래프가 균등분포가정 하에서 그려진 불연속적인 탈퇴력 그래프들의 중간을 부드럽게 가로지르고 있음을 확인할 수 있다.

지금까지 소수연령분포를 균등분포로 가정한 탈퇴력 그래프와 삼차 스플라인 함수를 이용한 탈퇴력 그 래프를 서로 비교해 보았다. 다음으로는 실제 데이터를 이용하여 수치비교를 해보도록 하겠다. Table 3.1 의 다중탈퇴표를 삼차 스플라인 함수를 이용하여 절대탈퇴표로 전환시켜보도록 하겠다. 식 (4.7)을 


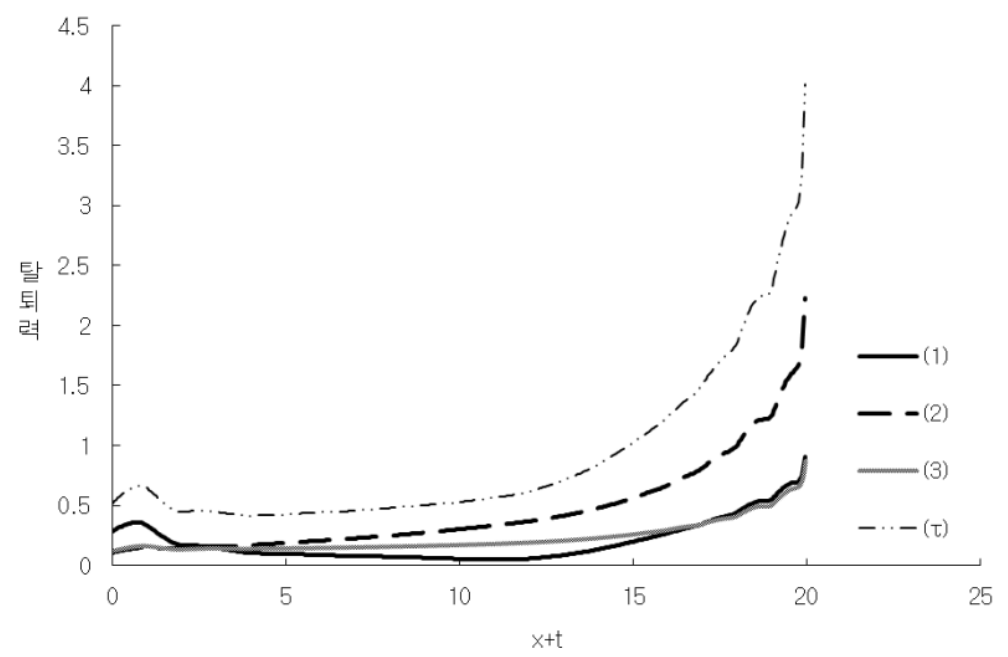

Figure 4.1. Forces of decrements

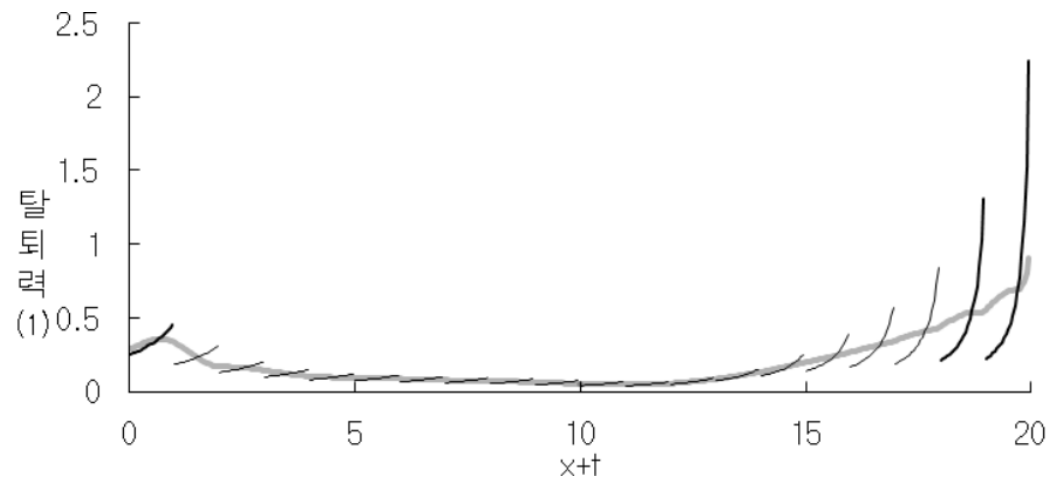

Figure 4.2. Smoothed force of decrement (1)

절대탈퇴표의 기간단위에 맞추어 아래와 같이 소수연령기간을 1 로 수정 후 이를 이용하면 Table 4.1과 같은 절대탈퇴표를 구할 수 있다.

$$
{ }_{1} p_{x}^{(j)}=\exp \left[-\int_{0}^{1}\left(\frac{\frac{d}{d t}\left(Q^{(j)}(x+t)\right)}{1-Q^{(\tau)}(x+t)}\right) d t\right] .
$$

참고로 식 (4.18)의 계산에는 심슨(Simpson)의 1/3수치적분법(Simpson공식은 $\int_{a}^{b} f(x) d x=(h / 3)$ $(f(a)+4 f(c)+f(b)), c=(a+b) / 2, h=(b-a) / 2$ 이며 위의 다중탈퇴표 계산에는 $h$ 를 0.001 로 놓고 계산함)을 이용하였다.

Table 4.1을 균등분포가정하에서 만들어진 절대탈퇴표 Table 3.3 과 비교해보는 것은 Table 3.3 또한 비 교기준이 될 수 있는 절대탈퇴표가 아니기 때문에 의미가 없다. 따라서 연속적인 탈퇴력 함수를 이용한 


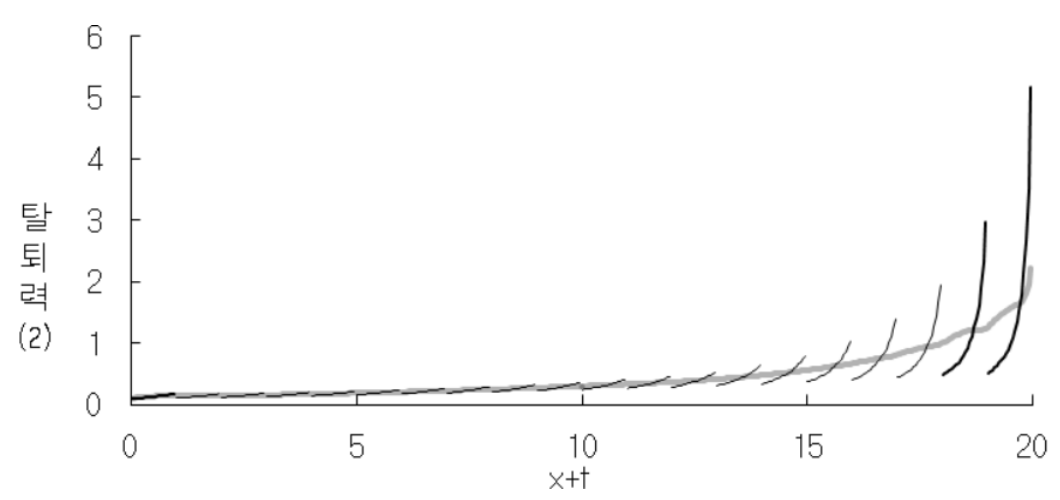

Figure 4.3. Smoothed force of decrement (2)

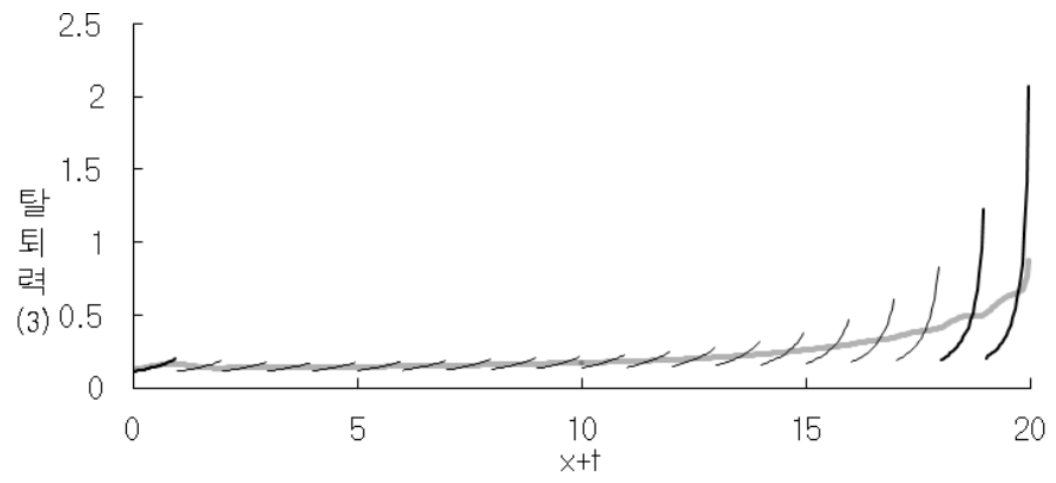

Figure 4.4. Smoothed force of decrement (3)

탈퇴모형간 전환방법의 오차를 살펴보기 위해서는 Table 4.1을 다시 다중탈퇴표로 전환하고 처음에 주 어진 Table 3.1과 비교해 보는 것이 분석을 용이하게 할 것이다. 따라서 Table 4.1과 소수연령기간을 1 로 수정한 식

$$
{ }_{1} q_{x}^{(j)}=\int_{0}^{1} \frac{\left(1-Q^{(\tau)}(x+t)\right) \frac{d}{d t}\left(Q^{\prime(j)}(x+t)\right)}{\left(1-Q^{(\tau)}(x)\right)\left(1-Q^{\prime(j)}(x+t)\right)} d t
$$

를 이용하여 다중탈퇴표를 구하면 Table 4.2 와 같고 Table 4.2 를 Table 3.4 와 비교하여 어느 표가 더 처 음에 주어진 다중탈퇴표 Table 3.1에 더 근접하는가를 비교하기 위해 Table 4.3을 작성해보았다. Table 4.3은 Table 4.2와 Table 3.1 간의 오차절대값과 Table 3.4와 Table 3.1간의 오차절대값을 비교하여 Table 4.2 의 오차절대값이 작을 경우를 '-', 클 경우를 '十'로 표시한 표이다. 표의 수치는 두 오차절대 값간의 차이를 나타낸다.

Table 4.3 의 결과에 따르면 총 60 개의 추정치 중 5 개를 제외한 나머지 55 개의 수치에서 연속적인 탈퇴 력을 이용하는 방법이 오차를 덜 유발하는 것으로 즉, 더 정밀한 추정을 하고 있는 것으로 확인되었다. 그리고 발생하는 오차를 Figure 4.5 와 같이 균등분포가정하에서의 오차절대값을 $x$ 축으로, 연속탈퇴력 가정하에서의 오차절대값을 $y$ 축으로 표시하면 균등분포가정하에서의 전환 시 발생하는 오차의 크기와 연속탈퇴력가정하에서의 전환 시 발생하는 오차의 크기가 서로 비례하는 것을 확인할 수 있다. 그리고 
Table 4.1. Associated single decrement rates(Cubic Spline)

\begin{tabular}{|c|c|c|c|}
\hline$x$ & $q_{x}^{\prime(1)}$ & $q_{x}^{\prime(2)}$ & $q_{x}^{\prime(3)}$ \\
\hline 0 & 0.286283 & 0.124823 & 0.139980 \\
\hline 1 & 0.209839 & 0.131517 & 0.135896 \\
\hline 2 & 0.148345 & 0.138393 & 0.132100 \\
\hline 3 & 0.114567 & 0.150140 & 0.132178 \\
\hline 4 & 0.092834 & 0.163292 & 0.133418 \\
\hline 5 & 0.086878 & 0.178351 & 0.136526 \\
\hline 6 & 0.078184 & 0.193889 & 0.140148 \\
\hline 7 & 0.072039 & 0.210776 & 0.144522 \\
\hline 8 & 0.065591 & 0.229336 & 0.149748 \\
\hline 9 & 0.056656 & 0.249701 & 0.155624 \\
\hline 10 & 0.050208 & 0.271257 & 0.162547 \\
\hline 11 & 0.049044 & 0.294830 & 0.170864 \\
\hline 12 & 0.067082 & 0.323146 & 0.182183 \\
\hline 13 & 0.102527 & 0.359512 & 0.197636 \\
\hline 14 & 0.152508 & 0.404845 & 0.218102 \\
\hline 15 & 0.207518 & 0.459321 & 0.244132 \\
\hline 16 & 0.264591 & 0.523065 & 0.276801 \\
\hline 17 & 0.326877 & 0.598333 & 0.319548 \\
\hline 18 & 0.400637 & 0.687210 & 0.379128 \\
\hline 19 & 0.497331 & 0.800767 & 0.474482 \\
\hline
\end{tabular}

Table 4.2. Multiple decrement rates(Cubic Spline)

\begin{tabular}{lccc}
\hline$x$ & $q_{x}^{(1)}$ & $q_{x}^{(2)}$ & 0.112254 \\
\hline 0 & 0.251612 & 0.099034 & 0.112797 \\
1 & 0.185870 & 0.108413 & 0.113764 \\
2 & 0.130188 & 0.119242 & 0.115256 \\
3 & 0.099910 & 0.131852 & 0.116988 \\
4 & 0.080034 & 0.145262 & 0.119146 \\
5 & 0.074017 & 0.159054 & 0.121742 \\
6 & 0.065991 & 0.173377 & 0.124761 \\
7 & 0.060016 & 0.188759 & 0.128271 \\
8 & 0.054009 & 0.205505 & 0.132286 \\
9 & 0.045990 & 0.224154 & 0.136833 \\
10 & 0.040022 & 0.243577 & 0.141977 \\
11 & 0.037954 & 0.264153 & 0.147683 \\
12 & 0.050043 & 0.285979 & 0.154054 \\
13 & 0.074014 & 0.310869 & 0.161054 \\
14 & 0.106143 & 0.338629 & 0.168801 \\
15 & 0.138117 & 0.369488 & 0.177268 \\
16 & 0.166177 & 0.403275 & 0.186508 \\
17 & 0.190095 & 0.439939 & 0.196431 \\
18 & 0.210211 & 0.477665 & 0.211384 \\
\hline 19 & 0.226171 & 0.511253 &
\end{tabular}


Table 4.3. Difference of conversion errors

\begin{tabular}{cccc}
\hline$x$ & $q_{x}^{(1)}$ & $q_{x}^{(2)}$ & -0.00030 \\
\hline 0 & -0.00077 & -0.00038 & -0.00015 \\
1 & -0.00029 & -0.00008 & -0.00000 \\
2 & +0.00014 & +0.00009 & +0.00004 \\
3 & +0.00002 & +0.00001 & -0.00000 \\
4 & -0.00010 & -0.00015 & -0.00003 \\
5 & -0.00016 & -0.00020 & -0.00006 \\
6 & -0.00021 & -0.00026 & -0.00012 \\
7 & -0.00024 & -0.00036 & -0.00018 \\
8 & -0.00028 & -0.00046 & -0.00027 \\
9 & -0.00031 & -0.00056 & -0.00040 \\
10 & -0.00033 & -0.00073 & -0.00053 \\
11 & -0.00036 & -0.00090 & -0.00076 \\
12 & -0.00059 & -0.00137 & -0.00107 \\
13 & -0.00107 & -0.00209 & -0.00166 \\
14 & -0.00165 & -0.00342 & -0.00260 \\
15 & -0.00269 & -0.00532 & -0.00420 \\
16 & -0.00417 & -0.00842 & -0.00692 \\
17 & -0.00681 & -0.01350 & -0.01177 \\
18 & -0.01130 & -0.02279 & -0.01828 \\
19 & -0.01934 & -0.03906 & \\
\hline
\end{tabular}

Table 4.3에서의 '+'가 발생한 부분을 보면 비록 연속탈퇴력가정으로 전환시킨 값의 오차가 균등분포가 정하에서의 오차절대값보다 크긴 하였으나 다른 오차절대값들에 비해 미미한 값이므로 큰 문제가 되지 않는다고 볼 수 있다.

균등분포가정하에서의 전환방법보다 오차가 큰 부분에 대한 원인을 생각해보면, 실제의 탈퇴력이 불연 속적일 수도 있고, 연속적이라 하더라도 삼차 스플라인 함수로 추정한 탈퇴력과는 거리가 있을 수 있기 때문으로 추측된다. 하지만 전체적인 추정치들이 균등분포가정하에서 추정한 값들보다 대부분 원래의 값에 근사하고 ' + '가 나타나는 수치들 또한 오차의 크기가 상대적으로 작으므로 큰 문제가 되지 않는다 고 생각한다. 따라서 다중탈퇴모형과 절대탈퇴모형간의 전환에는 연속탈퇴력가정을 사용하는 것이 더 낫다고 할 수 있다.

\section{5. 결론}

본 연구에서는 다중탈퇴모형과 절대탈퇴모형 그리고 두 모형간의 전환방법에 대하여 소개하였다. 선행 연구에서는 다중탈퇴율을 절대탈퇴율로 전환할 때 소수연령분포에 대하여 균등분포를 가정하거나 상수 탈퇴력을 가정하였고, 절대탈퇴율을 다중탈퇴율로 전환할 때에는 소수연령분포에 대하여 균등분포를 가 정하였다. 그런데 이러한 가정은 탈퇴력이 정수점에서 불연속이라는 특징이 있으며, 이러한 특징은 모 형간 전환 시 발생하는 오차와 무관하지 않았다.

본 연구에서는 위의 두 가정을 사용함으로써 나타나는 문제점과 개선책에 대하여 알아보았다. 삼차 스 플라인 보간법을 이용한 연속적인 탈퇴력 함수를 정의하고 다중탈퇴모형과 절대탈퇴모형간의 전환공식 을 유도하였으며, 수치 예를 통하여 기존의 가정하에서의 결과와 비교해보았다. 결과적으로 기존의 가 정보다 삼차 스플라인 보간법을 이용하여 연속적인 탈퇴력을 정의하는 방법이 더욱 정밀한 추정을 할 수 


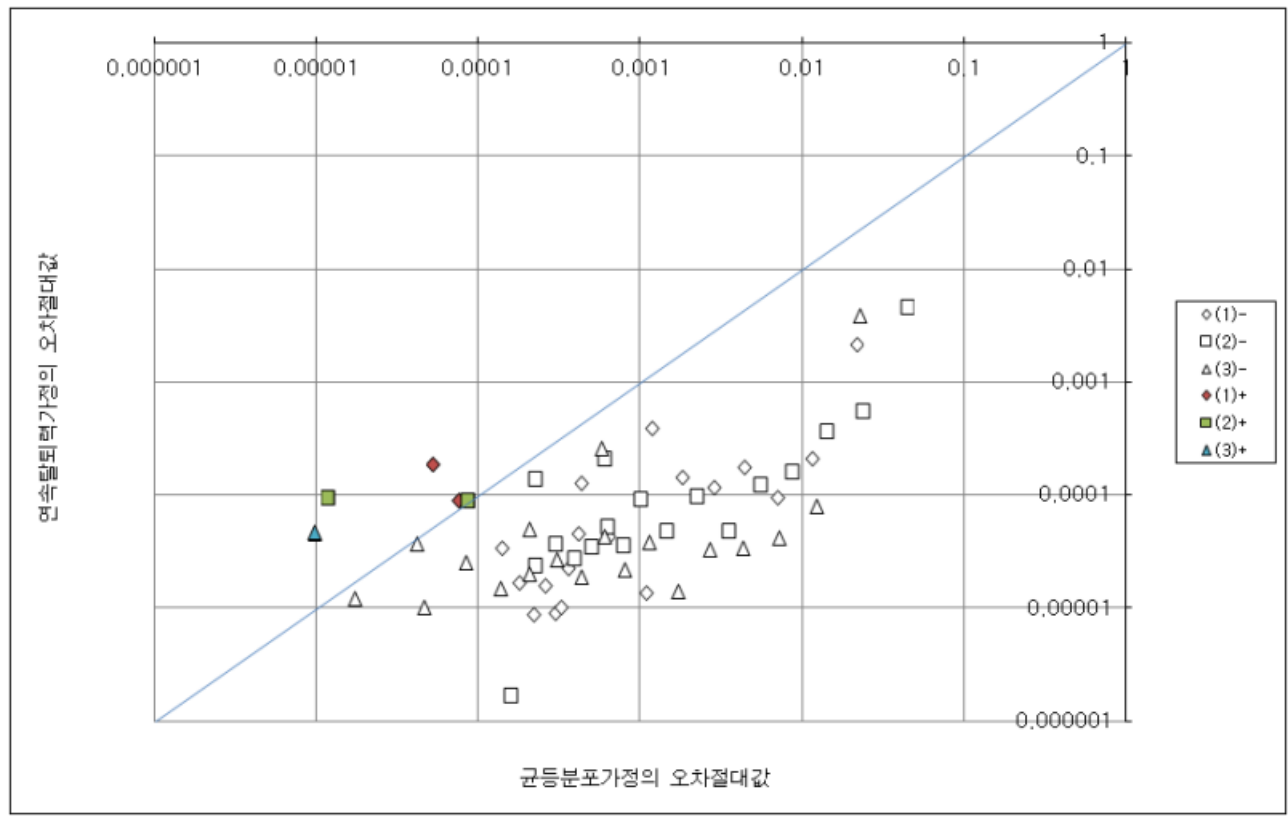

Figure 4.5. Scatter plot of conversion errors(오차절대값을 쉽게 비교할 수 있도록 눈금간격을 로그단위로 조정하여 표시하였으며, 45 도를 기준으로 위에 있는 좌표는 연속탈퇴력가정하에서의 오차절대값이 균등분포가정하에서의 오차절대값보다 큰 경우에 해당함)

있는 것으로 확인되었다.

본 연구에서는 스플라인 함수를 이용한 보간법을 사용하여 탈퇴력을 계산하였다. 이 방법은 수치해석 방법 중의 하나로서 연속적인 탈퇴력을 이용한 탈퇴율 전환을 위한 기본적인 접근 방법에 해당한다. 더 나은 방법을 찾기 위해서는 여러 방법론을 비교하는 추가적인 연구가 필요하다고 생각된다. 또한 스플 라인 방법을 이용하는 경우에도 수리적인 성질을 유도하는 연구가 향후 필요할 수 있다.

\section{References}

Bowers, N. L., Gerber, H. U., Hickman, J. C., Jones, D. A. and Nesbitt, C. J. (1997). Actuarial Mathematics, The Society of Actuaries

Carriere, J. F. (1994). Dependent decrement theory, Transactions of Society of Actuaries, 46, 45-74.

Daniel, J. W. (1993). Multiple decrement models and corresponding conditional single-decrement models, Actuarial Research Clearing House, 1, 229-237

Golbeck, A. L. (1986). Probabilistic approach to current life table estimation, The American Statistician, 40, 185-190.

Jones, B. L. and Mereu, J. A. (2000). A family of fractional age assumptions, Insurance: Mathematics and Economics, 27, 261-276

Jones, B. L. and Mereu, J. A. (2002). A critique of fractional age assumptions, Insurance: Mathematics and Economics, 30, 363-370

Kim, C. (2000). Numerical Analysis Using Matlab, 138-145, 162-165

Lee, H. (2008). Generalized conversion formulas between multiple decrement models and associated single decrement models, The Korean Journal of Applied Statistics, 21, To Appear

London, D. (1997). Survival Models and Their Estimation, ACTEX Publications 
Shiu, E. (1987). Multiple-decrements by Riemann-Stieltjes integration, Actuarial Research Clearing House, $1,1-4$

Willmot, G. E. (1997). Statistical independence and fractional age assumptions, North American Actuarial Journal, 1, 84-99 


\title{
삼차 스플라인 보간법을 활용한 탈퇴율 전환방법
}

\author{
김주경 $a \cdot 0$ 이항석 $b, 1$ \\ ${ }^{a}$ 동부화재, ${ }^{b}$ 성균관대학교 보험계리학과/수학과
}

(2013년 5월 23일 접수, 2013년 6월 14일 수정, 2013년 6월 17일 채택)

$$
\text { 요 약 }
$$

보험상품의 보험료를 계산하거나 리스크 관리를 하는 과정에서 다중탈퇴율이 필요하지만 경험 자료의 부족으로 절대 탈퇴율을 다중탈퇴율로 전환하여 많이 사용한다. 다중탈퇴율과 절대탈퇴율간의 전환에는 소수연령분포를 균등분포 로 가정하거나 탈퇴력을 상수로 가정하여 전환하는 방법을 주로 사용한다. 하지만, 이러한 가정하에서는 전환 시 오 차가 발생하므로 본 연구에서는 전환오차를 줄이기 위하여 소수연령분포를 삼차 스플라인 함수로 추정하여 전환하는 방법을 제안한다. 기존에 많이 사용하던 방법은 탈퇴력이 불연속적이라는 특징이 있었으나 새로이 제시하는 방법은 탈퇴력이 연속적이라는 측면에서 차이가 있다. 수치 예를 통하여 기존의 방법과 오차를 비교해 봄으로써 스플라인 추정법이 오차를 줄이는데 효과적임을 확인할 수 있다.

주요용어: 연속탈퇴력, 스플라인, 다중탈퇴율, 절대탈퇴율, UDD.

1교신저자: (110-745) 서울특별시 종로구 성균관로 $25-2$, 성균관대학교 보험계리학과/수학과, 부교수.

E-mail: hangsuck@skku.edu 